\title{
Rational Emotive Behavioural Therapy (REBT): A critical review.
}

\author{
Assumptor Mukangi.
}

\begin{abstract}
Aim of Essay
The aim of this essay is to critically evaluate Rational Emotive Behavioural Therapy (REBT) theory and practice in light of the professional ethics proposed by the Psychology profession.
\end{abstract}

\section{Introduction}

To commence this essay, REBT theory will be introduced then discussed along the Ethical guidelines governing the Psychology profession. This essay will try to address whether or not the REBT theory proposed by Ellis (1955) can stand alone in therapeutic sessions or whether the theory has to be used in collaboration with ethics in order to provide clients with the best service. It is crucial to assess the extent to which the theory can stand alone and still provide the best service to its consumers so that if it proves not to be a dependable theory on its own, then implementations can be made in light of ethics for the purpose of strengthening the theory and making it more applicable in the therapeutic sessions.

To start off a description of REBT theory and practice shall be illustrated. It should be noted that REBT is a form of Cognitive Behavioural Therapy (CBT), and that all the CBT approaches share similar themes, Corey (2009); Frank (2009). It should be noted that REBT was invented by Ellis (1955); after noting the lack of efficiency in psychoanalytic theory, Ellis (2002). This will then be followed by a comprehensive critical evaluation of REBT theory.

Key words: rational, behaviour. Therapy, emotive, cognitive

\section{REBT focus}

The REBT acronym stands for Rational Emotive Behaviour Therapy and was first introduced to the scene by Ellis (1955) after a long period of dissatisfaction with the psychoanalytic approach. Corey (2009) goes on to describe REBT as, "the active, directive, time-limited, present-centred, structural approach used to treat various disorders such as depression, anxiety and phobias," Corey (2009: 123). Another good definition is that proposed by Weishaar (1993) who has defined REBT as a Psychoeducational model. With the above definitions in mind, REBT can be better defined as a theory that portrays the role of cognitions, emotions and behaviour as interrelated dimensions which play a major role; and influence all aspects to human life, and particularly, how successful or unsuccessful individuals turn out to be.

REBT theory mainly focuses on how irrational thoughts affect people to the extent of causing detrimental effects and how these thoughts act as barriers to a happy self fulfilling life, Dryden (2003). Usually, the irrational thoughts held by a person are often 
congruent with their behaviour as can be reflected in the person's attitude which also has the cognitive, affective and behavioural components similar to those of REBT theory, Cacioppo \& Petty (1981). For example, Cognitive: I am unable to do Mathematics, affective: I feel bad just by thinking about Mathematics, Behavioural: the person puts in minimal effort towards Mathematics and as a result, they fail the subject. This implies that a negative attitude towards Mathematics makes a student fail their Maths until the day they will decide to change this attitude; they will forever get F grades in their Maths exams.

Though the word ethics is difficult to define, it has been used to refer to values which are used to guide the Psychology Profession, American Counselling Association (2005). On the other hand, The British Psychological Society (2006) has defined ethics as a guideline to professional code of conduct which incorporates and promotes the attitudes, behaviour and judgements expected from its members.

\section{Irrational thoughts in a nut shell.}

Batte (1996) defined rational thoughts as true thoughts and irrational thoughts as the false thoughts a person may have about themselves, others and how things in general must function to suit their needs. She goes on to explain that all thoughts, be they rational or irrational are the centre of self talk (intrapersonal speech) though rational thoughts will foster positive self talk, cognitions, emotions and behaviour whilst irrational thoughts breed negative intrapersonal speech which do not foster growth but rather have negative consequences on the person. This notion is also supported by Hassin, Uleman \& Bargh (2005) who believe that irrational thoughts are subconscious, act as motivation barriers and also interrupt rational thought patterns. In their perspective, Ellis \& Blau (1998) considered irrational thoughts as cognitions which contain words such as should and must. They believed that these types of self talks are irrational because if they do not go according to the person's plans and expectations; then negative consequences are inevitable as the likely end product.

Once the negative self talk enters the persons head, it affects everything they do from cognition, emotion and behaviour and how they cope with the ups and downs of life, Epstein (1998). After these irrational thoughts take over a persons thinking, the person is bound to act on them as evident in the individuals self fulfilling prophecy, Epstein (1998). The irrational self talk does not stop there as is evident in people who project their irrational thoughts onto other people and the world around them, Ellis \& Harper (1997). More evidence supporting the notion of the devastating effects of self talk comes from authors of self help books such as those by Dennis Waitley and Wayne Dyer which have explicitly acknowledged the role of irrational self talk as a barrier to goal achievement and particularly, positive self talk as the main factor which distinguishes successful people from those who are less successful in life.

As a result of these self talk, several implications can arise as result for instance, avoiding responsibility and blaming others for their downfall and incompetence or for other negative aspects in the person's life, as opposed to taking responsibility and being in control of one's life, Ellis et al (1997, 1998); Batte (1996). As a result, the person can 
end up feeling frustrated since they are unable to self actualize due to all the cognitive, behavioural and emotional barriers they have build up, Ellis et al (1997). Other severe consequences that can arise as a result entail procrastination, underachievement, blaming and psychological, emotional and behavioural problems, Batte (1996); which Ellis (1997) summarizes with the word 'disturbances'.

A good illustration of a person controlled by their negative cognitions is someone who hardly ever has anything positive to say about anyone or anything; they only see the negative aspect to everything. If these negative self talk are not reconstructed into healthy positive talk, then everything is bound to come crushing down as demonstrated in disturbances such as anxiety disorders and depression which are good examples of the devastating consequences of irrational thoughts, Ankrom (2009). Ankrom also argues that these expectations of must are irrational since they are not realistic to humankind and also because they force people not to accept themselves as they are but rather drive people to the extent of overwhelming themselves to try and be and do things which are impossible. E.g. being preoccupied with how things should be rather than accepting that humans do not have control over everything and accepting things the are not in control of.

Another shortfall of REBT theory is that it completely ignores the role played by individual differences bearing in mind that each one of us has their own individual threshold for succumbing to these irrational thoughts, DiGiuseppe (1996).

Another disadvantage is that the role of the diathesis stress model is also neglected, Bennett (2003); Ridgway (2007). With the ethics in mind, this implies that the theory has failed to account for all the possible causes and limited itself to one view point of which the APA (2002) code encourages continual education in other areas.

\section{REBT assumptions}

According to REBT theorists, the events that humans encounter in everyday life are not enough to cause problems (psychological, emotional and behavioural) however, the perception attached to the events is what really matters, Ellis (1955). In other words, the perceptions of the world around us are the contributing factors to irrational thoughts and other behaviours attached to these thoughts and all problems are the result of faulty thinking.

Corey (2005) emphasizes that this theory is only applicable to some people and particularly exempts people with 'limited Intelligence' (such as those with learning disabilities) and is therefore an intellectualized approach to therapy.This is further supported by code (IA) of feminist ethics (1999) which emphasizes the importance of Feminist therapists' accessibility to a wide range of clients. This approach to therapy violates the code since clients with Mental Retardation are exempted and also those with severe clinical disorders such as Autism Spectrum disorder due to the severity in both their cognitive and social skills, DSM-IV-TR (2000).

In addition to this, using just one theoretical orientation creates a lot of scepticism that the therapist can deal with all issues presented by clients in an effective and exhaustive 
manner, which is why the European Association of Gestalt Therapy (2008) ethics (B. 1. 7) stresses the importance of continual education in not only Gestalt therapy and techniques, but also in other fields of psychotherapy with an intention of both self development but mainly for the benefit of clients. The APA (2002) also stresses on the same. Hence, it is not clear whether a REBT practitioner would use Applied Behaviour Analysis for clients with Autism, refer to a specialist or just play along with the irrationality prophecy.

\section{REBT Concepts}

The key concept in REBT is that emotional problems descend from childhood, and as a result, invented the ABC theory of personality, (2005).

In the proposed model of personality, A refers to the trigger or event such as having an argument with a significant other. B serves as the client's belief system about the event. For instance, the person who had an argument might believe that the rest of their day has been ruined because of the argument they had earlier on. On the other hand, $\mathrm{C}$ represents the consequence which can either be adaptive or maladaptive depending on whether the A or event is perceived rationally or irrationally and the emotions arising as a result, Corey (2009). If the event is perceived rationally, then adaptive or constructive behaviour is portrayed e.g. relaxation, meditation or effective coping strategies, and the person moves on with the rest of the day, Willson et al (2006). However, if irrational thoughts (such as people should or must not argue with me) is attached to such events then problematic behaviour is evident in the individual; this is where psychological, behavioural and emotional problems start emerging from, Corey (2009). Willson et al (2006) lists a few examples of the consequences that can arise from these irrational beliefs which range from drinking to depression amongst many other disturbances which can be observed in day today life.

Though the above notion of irrationality seems plausible in some cases, it does not account for all psychological, behavioural and emotional problems, and hence, the theory should have either acknowledged this limitation or implemented the theory to account for other causal factors. As noted by Bennet (2003), there are various causes of psychological, behavioural and emotional problems which can be accurately accounted for by the Biopsychsocial model. E.g. If a family is has a history of depression, future generations are likely to inherit this biological disposition. However, whether an individual from this background develops depression will also be determined based on psychological factors such as consistently having irrational thoughts and, whether they have a good social support network and effective coping skills. Another perspective ignored is the role played by General Medical Conditions and as demonstrated, hypothyroidism, stroke and Multiple Sclerosis also cause depression; and all disorders also have their corresponding General Medical Conditions, DSM-IV-TR (2000). This violates the APA (2002) code which encourages psychologists to work using information that has been illustrated to be effective, as it ignores and limits itself to evidence in support of REBT and fails to consider factors such as those mentioned above.

Another ethical violation the REBT practitioners fail to state is the possibility of referring clients when they are not trained to work with them except in emergency cases, 
APA 2002.

\section{REBT Goals}

Since REBT theorists believe that peoples' problems are caused by the beliefs they hold, Corey (2005), it is no wonder that their therapeutic goal is to help clients develop a more positive outlook and the maintenance of positive cognitions by restructuring the irrational thoughts and beliefs they hold, Corey (2005). Another method used to combat these irrational goals is the tracking of cognitions so that the person may know when they start thinking irrationally and to take immediate action before these thoughts lead to maladaptive behaviour, by schema restructuring, Corey (2005).

This is a strong point in REBT theory since they do not only focus on the present situation but also teach the 'student' how to deal with future irrational thinking to avoid putting themselves in the same situations as they previously had, which is unlike other theories, Corey (2009). REBT also goes a step further by helping clients decide how to use their newly acquired knowledge in the future as opposed to becoming dependent and going to therapy every time things start going wrong in their lives, Corey (2009); which is in line with the APA (2002) notion of fostering autonomy in the client.

Another strength of REBT is that it is deemed to be the most effective form of Psychotherapy when combined with medication, in quite a number of clinical disorders and especially when it comes to treating depression, Bennett (2003). Though it is questionable as to whether REBT is effective in severe disorders such as Personality disorders, Schizophrenia and other Psychotic disorders due to the notion of intellectualized therapy amongst severely affected groups, Corey (2009).

Since REBT therapists believe that restructuring thoughts dramatically changes the persons behaviour and feelings, during therapy, the practitioner takes on the role of a teacher focussing on generating insight in the student in order for them to see how their irrational thoughts and negative self talk have contributed to the problems they are currently experiencing, better known as psychoeducation, Corey (2005). Ankrom (2009) also notes that the teacher also helps the student restructure and reword these irrational thoughts. For instance, if a clients negative self talk used to be 'I am ugly'; then this student can be helped reword this self talk in a more positive light such as 'I am better looking than some people'.

Bearing in mind that psychotherapy is supposed to be a partnership between the two parties as proposed by postmodern approaches, Corey (2009); this student teacher relationship may be perceived as exploitative since taking the role of a teacher, means that there is an unequal division of power which rightfully belongs to the client, Feminist ethics (II A). Or at least according to Corey, Corey \& Callanan (2003), this would constitute as withdrawing a client's rights from them since the therapist is not encouraging autonomy in the client but rather, the teacher has taken the dominant role in the therapeutic session which is contrary to the therapeutic structure proposed, APA 
(2002).

Another crucial aspect of this theoretical orientation is that it is also very confrontational, and especially during the first session, Corey (2009). According to the Reality Therapy (2002) code 2.2 Counsellors are urged to handle their client in a manner that fosters the clients development which does not seem to be the case in REBT therapy as all client's problems are not explored or even tackled; but rather they teach clients how to transform their thoughts into rational cognitions, Corey (2009). In addition to this, REBT theorists over confrontational style during the first sessions should be seriously reconsidered as it can affect rapport building at a time when it is very much needed, Snetselaar (1997).

Despite this, Snetselaar (1997) also offers a guideline on how to confront a client and particularly confronting in a non judgmental way and using some of the essential counseling skills such as paraphrasing and reflecting to confront a client in a skillful, thought out manner which will encourage the client to explore their situation as opposed to other methods which might make them go on the defensive and lead to other problems such as denial and partial examination which both act as barriers, and hinder further exploration; by the client and do not help them review their current situation, Snetselaar (1997). Hence, REBT practitioners should bear this in mind whilst confronting during the first session of therapy and if possible, confronting should be completely avoided in the first session. Though if one bears in mind that REBT is time limited and focused, it makes sense to confront the client from day one.

Another shortfall for this theory is that the therapist does not indulge in exploring the background of the emotional issues presented by their clients bearing in mind that they could be potential precipitators of the current situation, Corey (2009). All they do is just teach their student's how to think rationally regardless of the causal and maintenance factors, Corey (2005). This goes against the role of the therapist to help clients explore, verify their values and come up with their own solutions, which is the major role of psychotherapy in the first place, Corey (2009); and as stated in the preamble section of the APA (2002) code of ethics.

Ellis (1968) reacted to the above critique by claiming that carthasis only served the purpose of making the client feel better but other than that the client got worse which is why he invented REBT to conquer this problem, Corey (2009). In addition to this, Ellis

(1968) further proposed that psychoanalysis had an iatrogenic effect which only made the clients worse. Since psychologists are encouraged not to cause any harm, APA (2002), REBT practitioners' may be criticized under the premise that avoiding carthasis is directly harming a client by stopping the client from venting their emotions.

However, it is arguable that reconstructing negative to positive emotions can have a congruent positive effect on both cognition and behaviour, which reinforce a person's attitude, Cottam (2004). In a study by Staw, Sutton \& Pelled (1994) discovered that positive emotions had a positive influence on work. 
Unlike in REBT, this notion has been seriously considered and accounted for in the APA (2000) and especially by the European Association of Gestalt Therapy (2008) code B 1.2 which encourages Gestalt Therapists to either work collaboratively with other professionals or refer appropriately. Code 3.09 of the APA (2002) also emphasizes the same. The APA also goes further in code 10.04 and expands this by encouraging consultation with both colleagues and the clients when contemplating whether or not to offer parallel services for the purpose of minimizing both conflict and confusion in the client, APA (2002).

Considering the aspect of most clients will be under a care plan restricted to either a maximum of six sessions or twenty sessions per year, Corey et al (2003); the time limited aspect of REBT is therefore a great strength. REBT is also the preferred therapy type due to its goal oriented and short term therapeutic nature, Batte (1996).

Corey (2009) has also criticized REBT since the theory tends to ignore carthasis. For instance, consider the implications REBT could have for clients who are being abused; all they would do is to try and make the client perceive the abuse in a different light (not perceive it as something bad) and avoid the carthasis part, as much as possible which would mean that the client is discouraged from processing the traumatic event and as a result the event becomes frozen, Corey (2009). This would be the case unless the therapist decides to take extra training. When weighed against ethics, this seems to contradict the Canadian Psychological Association (2000) notion of respect in collaboration with that of the APA (2002) since ignoring the client's needs does not demonstrate respect for the client. In addition to this, it demonstrates a clear indication of conflict of interests between what the client and therapist want to achieve from the therapeutic session. Another plausible option is for the Psychotherapist to just keep referring. However, if they decide to keep referring, then there is a big problem of 'unfinished business' and hence, personal supervision and therapy is required to remedy this before it interferes with the therapists work, Corey et al (2003). The Canadian Psychological Association code of ethics (2000) stresses that it is the therapists' responsibility to keep a close track of their work and to know when to implement self care strategies to avoid burn out and other damaging effects of this burn out such as addictions.

According to REBT, we have the ability to be both rational and irrational though more often than not, we are inclined to thinking irrationally, Corey (2005). For this reason REBT therapists aim to change this self talk which they believe will also change subsequent behaviour and the emotions or feelings associated by both cognitions and behaviour.

\section{Relationship with therapist}

As Corey (2005) puts it "a warm relationship between the client and therapist's not essential," (p.124). This is because these practitioners believe that being overly concerned or overly empathetic could result in issues of transference, Corey (2009). Therefore, the therapist takes the role of an authoritative figure, Corey (2009). 
However, such an approach to therapy may not be beneficial to a client and especially because some patients diagnosed with major depression and particularly those experiencing both delusions and hallucinations as part of their depression think that they deserve to be treated in a terrible way since they believe that they are bad people, Casey \& Kelly (2007), DSM-IV-TR (2000). As a result, this may have a reinforcing effect for both their hallucinations and delusions, Casey et al (2007); because there is a lot of confronting in the initial stages of therapy and restricted empathy, Corey (2009). When compared with APA (2002), the theory falls short since the APA encourages that only techniques and methods that have been proven to work should be used. Hence, there is doubt that confronting the above mentioned clientele group would serve as a benefit and that research supports confronting these clients.

For this reason, REBT practitioners should either lay out a different code or include a section on how to handle clients based on the disorders they are diagnosed with in their current code; since confronting a depressed patient might not work. On the contrary, it is possible that over confronting a patient with a substance related disorder might however bring out the desired outcome from the patient; and especially those who resist therapy and decide to play a game of hide and seek with the therapist, Zimberg (1982).

Another shortfall is that REBT theory ignores other contributing factors such as the role played by power differences and gender roles as proposed by the Feminist theorists has not been accounted for, Corey (2009).

\section{Techniques of REBT}

These teachers call themselves eclectic since they deploy various techniques which fall under the cognitive, affective or behavioural dimensions, Corey (2009). For instance, when it comes to the cognitive techniques, their main aim is to change how clients think. For this reason, the clients are taught how to be scientists in the sense that they form their own hypothesis and test them out in the real world, Corey (2009). If the information obtained is inconsistent with the hypothesis, then this may result in incongruence forcing the client to change these unsupported irrational beliefs, Ankrom (2009); Corey (2009). At this stage, both the student and the teacher are very actively involved unlike in the treatment plan (where the therapist comes up with issues that the client needs to work on), Corey et al (2005).

In emotive techniques, the student is taught how to dispute their irrational beliefs by teaching the client how to unconditionally accept themselves despite their personal weaknesses, Corey (2009). According to Corey (2009), in imagery students imagine how they would like to think, feel and behave which helps establish 'new emotional patterns' to replace the maladaptive ones that existed before. Role playing also brings out people's underlying emotions for the events in question and is highly encouraged as an explorative and assessment tool, Corey (2009). Ellis also believed in using humour to show clients that they should not take life too seriously and also to enable them to laugh at themselves. He also used humour to confront his clients which is a subtle way of confronting and reduces the chances of the client being defensive since it is done in a non threatening 
way, Nelson-Jones (2000).

Another emotional technique used is role playing. Since some of the self talk that holds a person back from accomplishing their goals is subconscious, (Hassin et al 2005) role playing can help counteract this by arousing insight, Corey (2009).As the role play is ongoing, the REBT therapists is very attentive to the underlying irrational thoughts and brings any noted irrationalities to the clients awareness.

Several behavioural techniques are used by REBT clinicians. A good example of this is relaxation techniques commonly used in the treatment of phobias and anxiety disorders, Bennett (2003); Willson et al (2006). Though it can also be taught to everyone as a tool for clearing the mind and especially in stressful situations.

Though the techniques used by these theorists are divided into three categories, it is essential to note that the therapist uses them interchangeably and crosses over from emotional to behavioural and cognitive in no systematic order whatsoever since the technique used predominantly depends on session, client and what is being discussed at the time in question, Corey $(2009 ; 2005)$. In other words, there is no particular formula on how to use the techniques. It should also be noted that the techniques are not applied in a rigid manner just as the counselling skills; the therapist just needs to be very attentive and know when to use which technique as opposed to a formularization of these techniques.

Journaling is also very crucial at this point as it also helps the client see where they are and where they are going together with events that occur in their daily lives and their cognitive, affective and behavioural implications, Ankrom (2009). Meditation is also taught as a behavioural relaxation technique, Ankrom (2009).

Since the above techniques covering the cognitive, affective and behavioural components have been illustrated to be effective in the treatment of some disturbances, Willson et al (2006), this is consistent with the APA (2002) emphasise on using scientifically reliable and proven techniques.

\section{Conclusion}

On examining REBT against several codes of ethics, it is only appropriate to conclude that this theory is not anywhere close to explaining how clients should be catered for in consideration of the large number of ethical procedures proposed by both professional associations and those of other therapeutic orientations. This is particularly noted when REBT is compared to the APA and the European Association of Gestalt Therapists since these codes are more exhaustive when compared to other codes in the Psychology domain. In this case, the theory fails to account for some of the crucial ethics such as confidentiality, assessment, dual relationships with client and especially intimate relations. Other weakness of this theory is that REBT ignores other contributing factors such as the role played by General Medical Conditions, genetic and environmental contributors. Instead, the theory chooses to over emphasize the role played by irrational thoughts ignoring individual differences when it comes to developing psychological 
disorders. Having said this, it should also be noted that REBT also has various strengths such as its wide use amongst therapists due to its high levels of effectiveness. Another strong point is that it considers a persons cognitions, emotions and feelings which can be used to understand how people think and behave which is essential when it comes to deriving a treatment program for each individual.

\section{References}

American Psychiatric Association: Diagnostic and Statistical Manual of Mental Disorders, Fourth Edition, Text Revision. Washington, DC, American Psychiatric Association, 2000.

American Psychologist Association (2002). Code of ethics. Retrieved 22/02/2009 from http://www.apa.org/

Ankrom, S. (2009). Rational Emotive Behavioural Therapy. Using Rebt to treat Panic Disorder. Retrieved 23/08/2009 from http://panicdisorder.about.com/

Batte, M. (1996). ABC's of Rational Living. Retrieved 24/08/2009 from http://www.thejoveinstitute.org/

Bennet, P. (2003). Abnormal and Clinical Psychology. New York: Open University Press.

British Association of Counselling Psychotherapists (2009). Retrieved 02/03/2009 from http://www.bacp.co.uk/

Cacioppo, J. T., \& Petty, R. E. (1981). Cited in Merluzzi, T, V., Glass, C, R., \& Benest, M. (1981). Cognitive Assessment. New York: Guilford Press. Retrieved on 21/08/2009 from http://psychology.uchicago.edu/

Colledge, R. (2002). Mastering counselling theory. New York: Palgrave publishers.

Corey, G. (2009). Theory and practice of counselling and psychotherapy. California: Thomson Brooks/Cole.

Corey, G. (2005). Student manual theory and practice of counselling and psychotherapy. California: Brooks/Cole publishers.

Corey, C., Corey, M, A., \& Callanan, P. (2003). Issues and ethics in the helping professions. California: Brooks/Cole publishers.

Cottam, L, M. (2004). Introduction to Political Psychology. Retrieved on 21/08/2009 
from http://books.google.co.ke/

DiGiuseppe, R. (1996). The nature of irrational and rational beliefs: progress in rational emotive behaviour theory. Journal of Rational-Emotive \&Cognitive-Behaviour Therapy, 14(1). Retrieved 24/08/2009 from http://resources.metapress.com/

Dryden, W. (2003). Rational Emotive Behavioural Therapy: Theoretical developments. Windy Dryden (Ed.) London: Brunner-Routledge. Retrieved 21/08/2009 from http://books.google.co.ke/

Ellis, A. (1955).Cited in Corey, G. (2005). Student manual theory and practice of counselling and psychotherapy. USA: Brooks/Cole publishers.

Ellis, A. (1955). What is REBT? Retrieved on 21/08/2009 from http://www.rebtnetwork.org/

Ellis, A. (1968). Must Most Psychotherapists Remain as Incompetent as They Now Are? Journal of Contemporary Psychotherapy, 13 (1), Spring/Summer (1982). Retieved on 21/08/2009 from http://www.springerlink.com/

Ellis, A., \& Harper, R. (1997). Cited in Corey, G. (2009). Theory and practice of counselling and psychotherapy. California: Thomson Brooks/Cole.

Ellis, A., \& Blau, W. (1998). Cited in Corey, G. (2009). Theory and practice of counselling and psychotherapy. California: Thomson Brooks/Cole.

Ellis, A. (2002). Cited in Corey (2009). Theory and practice of counselling and psychotherapy. California: Thomson Brooks/Cole.

Epstein, S. (1998). Constructive thinking: the key to emotional intelligence. CITY: PUBLISHER. Retrieved on 24/08/2009 from

http://books.google.co.ke/

European Association of Gestalt Therapy (2008). Code of ethics. Retrieved 19/02/2009 from http://www.eagt.org/

Feminist ethics (1999). Retrieved 21/02/2009 from http://www.feminist-therapyinstitute.org/

Frank, F. (2009). American Psychologist, 64(3), 215-216. Retrieved 21/08/2009 from http://psycnet.apa.org/ 
Hassin, R, R., Uleman, J, S., \& Bargh, J, A. (2005). The new unconscious. Retrieved 24/08/2009 from http://books.google.co.ke/

Nelson-Jones, R. (2000). Six key approaches to counselling and psychotherapy. Retrieved 24/08/2009 from http://books.google.com/

Reality Therapy (2002). Code of ethics. Retrieved 12/02/2009 from http://www.wgii.ie/

Ridgway, I, R. (2007). Rational - Emotive Behaviour Therapy. Retrieved 24/08/2009 from http://www.myauz.com/

Snetselaar, L, G. (1997). Nutrition counseling skills for medical nutrition therapy. Retrieved 21/08/2009 from http://books.google.co.ke/

Staw, B, M., Sutton, R. I., \& Pelled, L. H. (1994). Employee Positive Emotion and Favourable Outcomes at the Workplace. Organization Science, 5 (1), 51-71. Retrieved 21/08/2009 from http://www.jstor.org/

Weishaar, M. (1993). Cited in Corey, G. (2009). Theory and practice of counselling and psychotherapy. California: Thomson Brooks/Cole.

Willson, R., Branch, R., (2006). Common-sense techniques for improving your mind and mood. Cognitive Behavioural therapy for dummies. West Sussex: John Wiley and Sons Ltd.

Zimberg, S. (1982). The clinical management of alcoholism. PublisherRoutledge Mental Health. Retrieved 22/08/2009 from http://books.google.co.ke/ 